\title{
Size Effect in Compression Fracture: Splitting Crack Band Propagation
}

\author{
By Zdeněk P. Bažant, ${ }^{1}$ Fellow, ASCE, and Yuyin Xiang ${ }^{2}$
}

\begin{abstract}
A simplified fracture-mechanics-based model of compression failure of centrically or eccentrically loaded quasi-brittle columns is presented and the size effect on the nominal strength of a column is predicted. Failure is modeled as propagation of a band of axial splitting cracks in a direction orthogonal or inclined with respect to the column axis. The maximum load is calculated from the condition that the energy released from the column due to crack band advance be equal to the energy consumed by the splitting cracks. The axial stress transmitted across the crack band is determined as the critical stress for buckling of the microslabs of material between the axial splitting cracks, and the work on the microslabs during postbuckling deflections is taken into account. The critical postbuckling deflection of the microslabs is determined from a compatibility condition. Under the assumption of small enough material inhomogeneities, the spacing $s$ of the splitting cracks is calculated by minimizing the failure load and is found to decrease with structure size $D$ as $D^{-1 / 5}$. The size effect on the nominal strength of geometrically similar columns is found to disappear asymptotically for small sizes $D$, and to asymptotically approach the power law $D^{-2 / 5}$ for large sizes $D$ (where $D=$ cross section dimension). However, when the material inhomogeneities are so large that they preclude the decrease of $s$ with increasing $D$, the asymptotic size effect changes to $D^{-1 / 2}$. The size effect intensifies with increasing slenderness of the column, which is explained by the fact that a more slender column stores more strain energy. The predicted size effect describes quite well previous tests at Northwestern University of reduced-scale tied reinforced concrete columns of different sizes (with size range 1:4) and different slenderness (ranging from 19 to 53). Finally, a simple modification is pointed out for the case of shear loading of concrete, in which a system of parallel tensile cracks in the diagonal compression direction develops before the maximum compressive stress is reached.
\end{abstract}

\section{INTRODUCTION}

The same as the tensile failure, the compression failure of quasibrittle materials such as concrete, rock, ice, ceramics, and composites often exhibits a size effect (e.g., van Mier 1986; Gonnermann 1925; Blanks and McNamara 1935; Marti 1989; Jishan and Xixi 1990). However, the compression failure, and especially its size effect, is more complex and less understood. Yet it often is the more important and dangerous mode of failure, which is highly brittle, lacking ductility. The reason is that compression failure is not controlled by a material strength criterion, as assumed in nearly all practical applications up to now. Rather, as suggested or implied by some researchers (e.g., Ingraffea 1977; Bažant et al. 1993; Bieniawski 1974; Hoek and Bieniawski 1965; Cotterell 1972; Paul 1968) and described mathematically in this paper, the compression failure in quasi-brittle materials is caused predominantly by the release of stored energy from the structure. This aspect is similar to fracture mechanics of tensile cracks.

Whenever the consequence of material failure is the postpeak softening or the lack of ductility, a size effect must be expected. The size effect is the most important practical consequence of fracture phenomena, and observation of the size effect is an effective way to calibrate the parameters of a fracture model. For this reason, the analysis in the present paper, which expands on a previous conference presentation (Bažant 1994; Bažant and Xiang 1994), will focus on the effect of structure size on the nominal strength of quasibrittle structures failing in compression. The objectives are to give a simple, intuitively clear explanation of the phenomenon of size effect, to formulate a simplified model for the global mechanism of propagation of compression fracture, and finally to use this

\footnotetext{
'Walter P. Murphy Professor of Civil Engineering and Materials Science, Northwestern Univ., Evanston, IL 60208-3109.

${ }^{2}$ Grad. Res. Asst., Northwestern Univ., Evanston, IL.

Note. Associate Editor: Robert Y. Liang. Discussion open until July 1, 1997. To extend the closing date one month, a written request must be filed with the ASCE Manager of Journals. The manuscript for this paper was submitted for review and possible publication on December 18, 1995. This paper is part of the Journal of Engineering Mechanics, Vol. 123, No. 2, February, 1997. CASCE, ISSN 0733-9399/97/0002$0162-0172 / \$ 4.00+\$ .50$ per page. Paper No. 12232 .
}

model to determine the size effect and compare the results to test data.

\section{CONCEPTS AND MECHANISMS OF COMPRESSION FRACTURE}

In ductile metals, compression failure (as well as tensile failure) is caused by plastic slip on inclined shear bands. This type of failure is ductile, without any significant postpeak decrease of the applied load. It does not cause any size effect.

In quasibrittle materials, however, such ductile compression failure is possible only under extremely high lateral confining pressures, which is a case beyond the scope of this study. Such pressures lacking, the shear slip in quasibrittle materials such as concrete cannot develop. The interlock of rough surfaces of cracks inclined to the principal compressive stress direction prevents any slip, unless the cracks are already widely opened and the material near the crack is heavily damaged. Macroscopically, of course, shear failures are often observed, but their microscopic physical mechanism is different. It normally consists of tensile microcracking inclined to the shear direction.

On the microscale, one can discern the following three different mechanisms triggering compression fracture:

1. Pores with microcracks. It has long been known that porosity is the main controlling factor for compression strength of various materials. The linear elastic fracture mechanics (LEFM) was used to show that pores cause axial tensile splitting microcracks to grow from the pore under a compression load of increasing magnitude [Fig. 1(a); see e.g., Cotterell (1972); Sammis and Ashby (1986); Ashby and Hallam (1986); Kemeny and Cook (1987, 1991); Steif (1984); Ingraffea (1977); Zaitsev and Wittmann (1981); Wittmann and Zaitsev (1981); Zaitsev (1985); Fairhurst and Cornet (1981); Ingraffea and Heuzé (1980); Kemeny and Cook $(1987,1991)$; Sheffy et al. (1986); Nesetova and Lajtai (1973); Carter et al. (1992); Carter (1992); Yuan et al. (1993)]. An important point to note is that these axial cracks can grow from the pore only for a certain finite distance, which is of the 
(a)

(b)

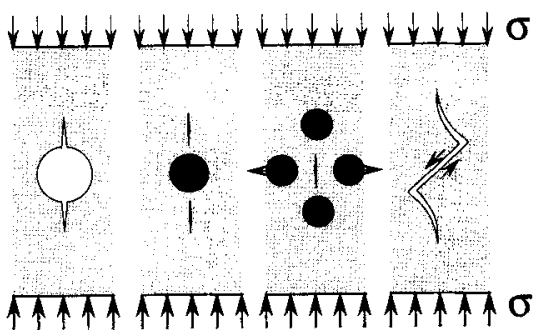

(e)

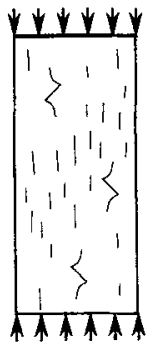

FIG. 1. Microscoplc Mechanisms of Compression Fracture

same order of magnitude as the pore diameter. Therefore, this mechanism cannot explain the global fracture. A similar conclusion applies to various configurations of several pores that enhance the local transverse stresses or produce shear stresses on axial planes.

2. Inclusions with microcracks. A stiff inclusion, for example, a rigid piece of stone aggregate in a softer mortar matrix, causes tensile stresses at a certain distance above and below the inclusion, which can produce short tensile splitting microcracks [Fig. 1(b)]. More effective generators of transverse tensile stresses in a macroscopically uniform uniaxial compression field are various groups of inclusions, such as a group of two inclusions pressed between two others [Fig. 1(c)]. Such a failure mechanism (proposed for concrete long ago by Brandtzaeg and by Baker) can be shown to produce short tensile splitting microcracks between the inclusions [Fig. 1(c)]. Again, an important point is that the cracks remain short, of the same order of magnitude as the inclusion, and so the global fracture cannot be explained.

3. Wing-tip microcracks. In a material without pores and without inclusions, cracks in a macroscopically uniform uniaxial compression field can be produced by weak inclined interfaces between crystals. Slip on an inclined crack causes the growth of curved cracks gradually turning into the direction of compression, called wing-tip cracks [Fig. 1(d)]. Such cracks have been extensively analyzed by fracture mechanicists, both numerically and analytically (Ingraffea 1977; Ashby and Hallam 1986; Nemat-Nasser and Obata 1988; Horii and Nemat-Nasser 1982, 1986; Kachanov 1982; Lehner and Kachanov, in press, 1996; Batto and Schulson 1993; Schulson and Nickolayev 1995), and curved crack growth under compression has been clarified (Cotterell and Rice 1980). A fully realistic analysis of wing-tip cracks would have to be three-dimensional, which has apparently not yet been accomplished. It is important to note that the length of the wing-tip cracks is again of the same order of magnitude as the length of the inclined slipping crack, and so the global fracture cannot be modeled.

The objective of the present study is the formulation of a simplified model for the global mechanism of compression failure, particularly for the accompanying size effect. This is a much more complex problem than the tensile fracture.

In regard to the global fracture mechanisms on the macroscale, one may distinguish those that cause a global energy release with size effect from those that do not. A mechanism that does not cause global energy release is represented by the propagation of a continuous macroscopic splitting crack [Fig. 2(c)], which is known to occur in small laboratory test specimens when the ends are sliding with negligible friction. While a transverse tensile crack causes a change in the macroscopic stress field [Fig. 2(a)], a splitting macrocrack does not change the macroscopic stress field [Fig. 1(b)], and so it causes no global release of energy. The energy to form the crack and
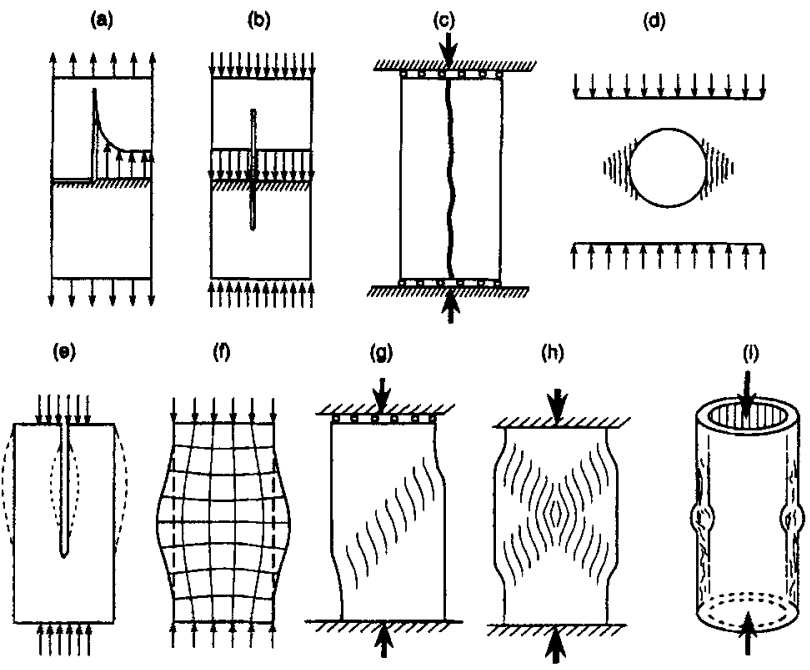

FIG. 2. Global Mechanisms and Hypotheses on Compression Fracture

propagate it must come from a local mechanism, such as the release of stored energy from the fracture process zone. [This energy must be calculated from the triaxial constitutive relation; Bažant and Ožbolt (1992)]. Because of the absence of a global energy release, this type of compression failure cannot cause any size effect, as confirmed by the numerical results of Bažant and Ožbolt (1992) and Droz and Bažant (1989). Since our interest is in failures in which a size effect has been observed, the splitting macrocrack will not be analyzed.

If the load required to drive the local mechanism of axial splitting crack propagation is higher than that required to drive the global mechanism of failure due to energy release, the global mechanism will occur. As we will see, the global mechanism is accompanied by size effect, and so it will prevail for sufficiently large sizes.

The mechanism of global energy release must obviously involve some sort of transverse propagation of a cracking band (or damage band). Such a band may logically be supposed to consist of densely distributed axial splitting microcracks. The weakening of the material by microcracks may be expected to cause internal buckling.

Although important contributions have been made by mathematical modeling of the aforementioned mechanisms in which cracks are engendered by pores, inclusions, and slips on inclined interfaces, it must be recognized that these contributions explain only the microscopic initiation of compression fracture. They do not describe the global, macroscopic compression failure. The microcracks can grow in the compression direction only for a limited distance under increasing load but the maximum load is not reached according to these mechanisms. In the axial cross sections through a specimen under a uniform uniaxial compression stress field, each of these three mechanisms produces a profile of self-equilibrated, alternatively tensile and compressive, microstresses, which average to a zero transverse stress on the macroscale [Fig. 2(d)].

It cannot be denied that the compression splitting fracture begins microscopically as a series of straight, wing-tip, or other microcracks shown in Fig. 1(a-d), but how these microcracks connect and propagate macroscopically is not explained by the aforementioned microscopic mechanisms. This needs to be described by a global mechanical model. A simple form of such a model, simple enough to allow a straightforward analytical solution, is proposed in this study. The model is based on the hypothesis that the axial straight or wing-tip microcracks can become stacked in the lateral direction to produce a transverse (inclined or orthogonal) compression-shear 
band (in rock mechanics this is also called "en-echelon" cracks).

Relatively little work has been done on the global mechanism of compression failure. Biot (1965), in relation to his previous model of internal instabilities such as strata folding in geology, proposed that compression failure involves internal buckling of a three-dimensional continuum, and pioneered elastic continuum solutions of such instabilities [Fig. 2(f,g)]. Biot's studies, however, were limited to elastic materials without damage, and consequently the predicted critical stresses for such instabilities were too high by far. Bažant (1967) applied finite strain analysis to the bulging and other internal instabilities of thick compressed solids made orthotropic by microcracking damage [Fig. 2(f,g)] and showed that such instabilities can explain the failure of an axially compressed fiber-reinforced composite tube, describing realistically the dependence of the failure stress on the ratio of the wall thickness to the diameter (also Bažant and Cedolin, 1991, Sec. 11.8).

The role of buckling was further clarified in an important contribution by Kendall (1978), who studied the axial splitting fracture of a prism compressed on only a part of its end surfaces [Fig. 2(d)]. He managed to obtain rather simple formulas. Simple formulas were also derived for axially compressed fiber-reinforced laminates in which internal buckling is engendered by the waviness of fibers in the layers of fabric [Bažant 1968; Bažant and Cedolin 1991 (Section 11.9)]. In Kendall's model, however, the buckling of the specimen halves was caused by load eccentricity. His model could not explain the axial splitting fracture of a compressed specimen uniformly loaded over the entire end surface, for which the critical buckling stress is obtained much too high from his model. Nevertheless, the notion that instability of a specimen weakened by axial cracks is part of a global compression failure mechanism has been clearly established.

Another phenomenon that drives the compression failure is a release of the stored energy, the same as in tensile fracture. This concept was introduced in the analysis of stopes in very deep mines in Transvaal, South Africa, in the 1960s, and an empirical failure criterion based on the energy release from the rock mass as a function of the length of the stope was established (and simulated by an electric analog model at the Chamber of Mines in Pretoria, South Africa) (Hoek and Bieniawski 1965; Bieniawski 1974).

The global energy release aspect was brought into the modeling of compression failure in a study of the compression breakout of boreholes in rock (Bažant et al. 1993). A band of parallel splitting cracks was considered to propagate from the sides of the borehole, driven by the release of strain energy from the surrounding rock mass. It was shown that such a model predicts a size effect, which basically agrees with the recent test results of Haimson and Herrick (1985), Carter (1992), and Carter et al. (1992). This solution contrasts with previous plasticity solutions of borehole breakout, which predict no size effect. The stored energy release due to propagation of a band of axial splitting cracks, coupled with buckling of the slabs of material between the cracks, have been two principal aspects of a model recently proposed by Bažant et al. (1993), which will serve as the basis of the present analysis.

A nonlocal constitutive damage model capable of capturing the energy release was used by Droz and Bažant (1989) and Bažant and Ožbolt (1992) for finite element modeling of compressed rectangular specimens. These studies predicted for such specimens no significant size effect. The absence of size effect does not contradict the available test data for normalsize laboratory specimens. These specimens are too small to exhibit size effect. For the size effect due to energy release to get manifested, the compressed structure must be much larger than the localized compression cracking zone, which is not the case for normal test specimens.

The delamination fracture, in which models involving buckling and fracture propagation are well established, is a rather special and broad topic, which lies beyond the scope of the present paper. So does a possible fractal aspect of the problem; for example, fractal comminution and fragmentation of crushed sea ice (Palmer and Sanderson 1991).

\section{ENERGY ANALYSIS OF COMPRESSION FAILURE OF COLUMN}

The plastic limit state analysis of compression failure is based on the hypothesis that a system of yielding surfaces creating a single-degree-of-failure mechanism develops at maximum load. With the exception of the case of strongly confined concrete under very high pressure, such a hypothesis, however, appears to be unrealistic for four reasons: (1) The load-deflection diagram for plastic failure of a stocky column would have to end with a horizontal yield plateau, but in reality there is postpeak softening; (2) material tests indicate that concrete is incapable of plastic deformation except under high confining pressure; (3) in experiments, the compression failure is actually seen to be caused by fractures; and (4) according to the recent reduced-scale tests (Bažant and Kwon 1994), there is a strong size effect, which is of the type associated with the propagation of crack bands.

In brittle or quasibrittle materials, compression failure begins by the formation of axial splitting cracks. However, the axial splitting cracks do not change the macroscopic continuum stress state due to uniaxial compression. Consequently, they cause no energy release, and so they cannot by themselves be the mechanism of compression failure, and cannot control the failure load. They can only be the mechanism that triggers the macroscopic compression failure. As already suggested in Bažant (1994), it is proposed that the principal mechanism of compression failure of a concrete column is sideways propagation of a band of parallel axial splitting cracks, in a direction either orthogonal or inclined with respect to the direction of compression, as shown in Fig. 3. This figure shows several alternative geometries of the crack band, which lead, according to the approximate analysis to be presented, to equivalent results.

We will analyze compressed columns of different sizes $D$, geometrically similar in two dimensions [Fig. 3(a)]. The column length is $L$, the thickness is $b=1$, and the width is taken as the size, or characteristic dimension, $D$. The bottom of the column is fixed. The top of the column is loaded by axial compressive force $P$ of eccentricity $e$. To compare the load capacity of columns of different sizes, we define the nominal strength of the column, $\sigma_{N}=P_{\max } / b D$ where $P_{\max }$ is the max-

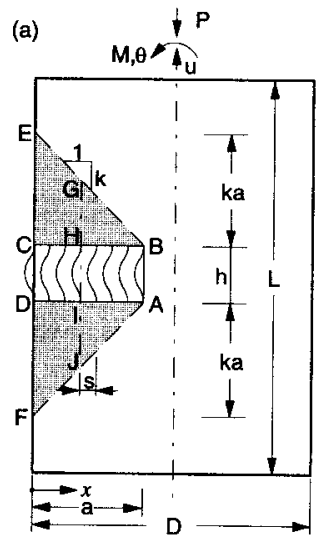

(b)

(c)
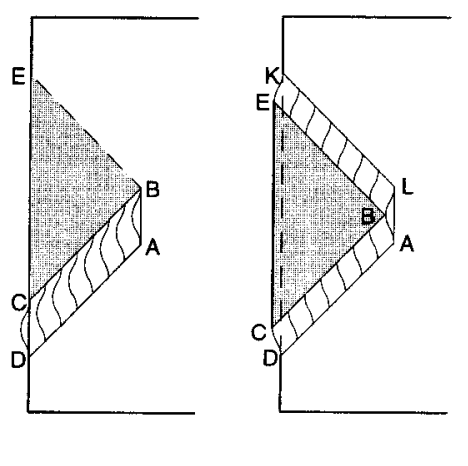

FIG. 3(a-c). Splitting Cracks, Buckling of Microslabs, and Stress Relief Zone 
(d)
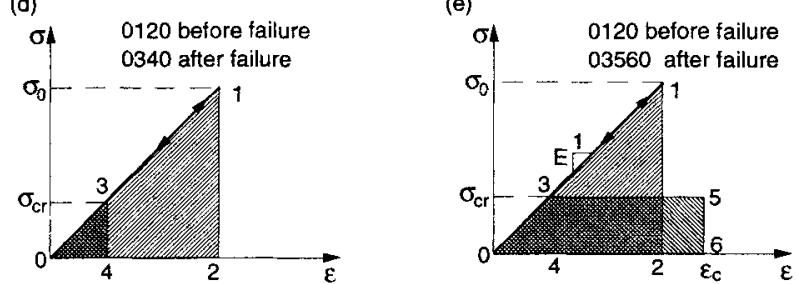

FIG. 3(d,e). Stress-Strain Diagrams with and without Buckling, and Areas Representing Strain Energy Changes

imum value of load $P$. We are interested in failure under loadcontrol conditions (dead load), which means that failure occurs at maximum load. Therefore, $P$ remains constant during the small deformation increment representing failure.

The initial normal stress in the cross sections before any fracturing is

$$
\sigma_{0}(x)=-\frac{E}{L}\left[u+\theta\left(\frac{D}{2}-x\right)\right]
$$

where $E=$ Young's elastic modulus; $u=$ load-point axial displacement; $\theta=$ rotation of top end; and $x=$ transverse coordinate measured from compressed face [Fig. 3(a)]. We now assume that, at a certain moment of loading, axial cracks of spacing $s$ and length $h$, forming a band as shown in Fig. 3 $(\mathrm{a}-\mathrm{c})$, suddenly appear and the microslabs of the material between the axial cracks, behaving as beams of depth $s$, lose stability and buckle. This can happen in any one of the three mechanisms shown in Fig. $3(\mathrm{a}-\mathrm{c})$ and for all of them the mathematics turns out to be identical. If the length of the cracks in the two inclined bands in Fig. 3(c) is denoted as $h /$ 2 , the critical stress for the microslab buckling for all the cases shown in Fig. 3(a-c) is, according to Euler's formula for columns,

$$
\sigma_{c r}=-\frac{\pi^{2} E s^{2}}{3 h^{2}}
$$

The key idea is the calculation of the change in the stored strain energy caused by buckling. On both sides of the crack band, there is obviously a zone in which the initial stress $\sigma_{0}$ is reduced. For the sake of simplified analysis, we assume that the stress in the shaded triangular zones of Fig. $3(\mathrm{a}-\mathrm{c})$ is relieved to the value of $\sigma_{c r}$. Further, we assume that outside these zones the initial stress does not change (this is of course a simplification of reality, because stress concentration arises ahead of the crack band).

The triangular stress relief zones are limited by the so-called "stress diffusion lines" of slope $k$, whose magnitude is of the order of 1 . The value of $k$ can be determined by experiment or by solution of the elastic stress field. Approximately, the value of $k$ may be taken as the value that gives the exact stress intensity factor of the edge-cracked half-space according to linear elastic fracture mechanics, which is $k=\pi\left\{\left[f_{1} D+f_{2} 6(e\right.\right.$ $+w)] /[D+6(e+w)]\}^{2}$, in which $f_{1}(a / D)$ and $f_{2}(a / D)$ can be found in handbooks (Tada et al. 1985; Murakami 1987). However, the value of $k$ need not be known for our purposes. The only important point is that $k$ is a constant having the same value for columns of different sizes.

The strain energy density in the shaded triangular stress relief zones before and after fracture is equal to the areas of triangles 0120 and 0340 in Fig. 3(d). So, the loss of strain energy density at points on a vertical line of coordinate $x$ is

$$
\Delta \bar{\Pi}_{r}=\frac{\sigma_{0}^{2}(x)}{2 E}-\frac{\sigma_{c r}^{2}}{2 E}
$$

The situation is more complicated in the crack band. The microslabs buckle, and the energy associated with the postbuckling deflections must be taken into account. This is an important point for the present solution (Bažant 1994). The strain energy density before buckling of the microslabs is given by the area 0120 in Fig. 3(e). The well-known solution of postbuckling behavior of columns [Bažant and Cedolin 1991 (Sections 1.9 and 5.9)] indicates that the stress in the axis of the microslab follows, after the attainment of the critical load of the microslab, the straight line 35, which has a very small positive slope (precisely equal to $\sigma_{c r} / 2$ ). This slope is far smaller than the slope $E$ before buckling and can, therefore, be neglected. So the postbuckling behavior in Fig. 3(e) is approximately a horizontal plateau 35 (however, this is not the same as plastic behavior because unloading proceeds along the path 530). Because the microslabs remain elastic during buckling, the stress-strain diagram 035 is fully reversible and the energy represented by the area under this diagram is the stored elastic strain energy. The triangular area 0340 is Fig. 3 (e) represents the axial strain energy density of the microslabs and the rectangular area 35643 represents the bending energy density. The change in strain energy density in the microslabs is the difference of areas 0120 and 03560 in Fig. 3(e); that is

$$
\Delta \bar{\Pi}_{c}=\frac{\sigma_{0}^{2}(x)}{2 E}-\left[\sigma_{c r} \varepsilon_{c}(x)-\frac{\sigma_{c r}^{2}}{2 E}\right]
$$

where $\varepsilon_{c}=$ axial strain of microslabs in crack band after buckling [it is important to realize that this strain is generally not equal to 04 or 02 in Fig. 3(e)].

Integration of (3) and (4) yields the total loss of potential energy at constant $u$ and $\theta$

$$
\begin{aligned}
\Delta \Pi & =-\int_{0}^{a}\left(\frac{\sigma_{0}^{2}(x)}{2 E}-\frac{\sigma_{c r}^{2}}{2 E}\right) 2 k(a-x) d x \\
& -\int_{0}^{a}\left\{\frac{\sigma_{0}^{2}(x)}{2 E}-\left[\sigma_{c r} \varepsilon_{c}(x)-\frac{\sigma_{c r}^{2}}{2 E}\right]\right\} h d x
\end{aligned}
$$

where $a=$ horizontal length of crack band [Fig. 3(a-c)]. The rate of this energy loss must be equal to the rate at which the energy is consumed by formation of the axial splitting cracks. Thus, the energy balance criterion of fracture mechanics may be written as

$$
-\left[\frac{\partial \Delta \Pi}{\partial a}\right]_{\theta, u}=\frac{\partial}{\partial a}\left(G_{f} h \frac{a}{s}\right)=G_{f} \frac{h}{s}
$$

where $G_{f}=$ fracture energy of axial splitting cracks, assumed to be material property; and $G_{f} h / s=G_{f}^{*}$ represents fracture energy of crack brand.

The axial strain in the crack band can be determined from the compatibility condition. The blank zone outside the shaded triangular stress relief zone [Fig. $3(\mathrm{a}-\mathrm{c})$ ] behaves during buckling as a rigid body because the load, and thus also the stress in this zone, are constant during the deformation increment representing failure. The line segment $G J$ in Fig. 3(a) at any $x$ does not change length during buckling. Expressing the change of length of this segment on the basis of $\sigma_{c r}, \varepsilon_{c}$, and $\sigma_{0}$ and setting this change to zero, one acquires the following compatibility condition:

$$
\varepsilon_{c}(x)=\frac{\sigma_{0}(x)}{E h}[h+2 k(a-x)]-\frac{2 k}{h}(a-x) \frac{\sigma_{c r}}{E}
$$

The length $h$ of the axial cracks, representing the width of the crack band in Fig. 3(a,b) or double the crack band width in Fig. 3(c), is an important parameter that must be determined. The critical stress according to (2) would decrease with increasing $h$, and so the largest energy release would be obtained for $h \rightarrow \infty$. Since the largest energy release is what 
must happen (because of thermodynamic considerations; [Bažant and Cedolin 1991 (chapters 10 and 12)]\}, the prediction would be $\sigma_{c r}=0$, which, however, is unreasonable.

In a recent study of the role of axial splitting cracks in borehole breakout (Bažant et al. 1991), the microslab buckling was assumed to be opposed by shear stresses on the microcracks taken as proportional to the slip on the microcracks. That assumption leads to a more complicated formula for $\sigma_{c r}$ than (2), and it is noteworthy that $\sigma_{c r}$ then attains a minimum for a certain finite value of $h$, which permits $h$ to be calculated. A similar approach would be possible for the present problem. However, to keep the solution simple, we will not specifically consider shear stress transmission across the cracks and will simply assume that $h$ is a constant to be determined empirically.

In tied reinforced concrete columns, there is also another feature affecting $h$-the ties, whose spacing probably poses an upper limit on the crack length.

Now we can substitute (1)-(4) into (5) and integrate. The result is

$$
\begin{gathered}
\Delta \Pi=\frac{D^{2}}{6 E}\left[2 k \sigma_{2}^{2} \alpha^{4}+4\left(\bar{h} \sigma_{2}^{2}-k \sigma_{2} \sigma_{3}\right) \alpha^{3}\right. \\
\left.\left.+3\left(k \sigma_{3}^{2}-2 \bar{h} \sigma_{2} \sigma_{3}\right) \alpha^{2}+3 \bar{h} \sigma_{3}^{2} \alpha\right)\right]
\end{gathered}
$$

in which

$\sigma_{1}=E \frac{u}{L}+\sigma_{c r} ; \quad \sigma_{2}=E \frac{\theta D}{2 L} ; \quad \sigma_{3}=\sigma_{1}+\sigma_{2} ; \quad \alpha=\frac{a}{D} ; \quad \bar{h}=\frac{h}{D}$

Substituting this into the energy criterion (6) of crack band propagation and noting that $\partial / \partial a=(1 / D) \partial / \partial \alpha$, we get

$$
\begin{aligned}
& 8 k \sigma_{2}^{2} \alpha^{3}+12\left(\bar{h} \sigma_{2}^{2}-k \sigma_{2} \sigma_{3}\right) \alpha^{2}+6\left(k \sigma_{3}^{2}-2 \bar{h} \sigma_{2} \sigma_{3}\right) \alpha \\
& \quad+3 \bar{h}\left(\sigma_{3}^{2}-2 E G_{f} / s\right)=0
\end{aligned}
$$

This equation represents the failure condition; that is, the condition of crack band propagation at maximum load. It is a condition expressed in terms of displacements $u$ and $\theta$ because $\sigma_{1}, \sigma_{2}$, and $\sigma_{3}$ are functions of $u$ and $\theta$. However, we are interested in the nominal strength $\sigma_{N}$, which is a parameter of the maximum load $P$. To obtain the failure conditions in terms of the load, we substitute the expressions

$$
\sigma_{1}=\sigma_{c r}-\sigma_{N} ; \quad \sigma_{2}=-\sigma_{M} ; \quad \sigma_{3}=\sigma_{c r}-\sigma_{N}-\sigma_{M}
$$

in which

$$
\sigma_{N}=\frac{P}{b D} ; \quad \sigma_{M}=\frac{M D}{2 I}=\frac{6 M}{b D^{2}} ; \quad M=P(e+w)
$$

Here $P$ is positive when compressive; $M=$ bending moment at location of crack band; and $w=$ column deflection [Fig. 4(c)] at that location (maximum deflection within the column length). For a stocky column, one may use $w \approx 0$. For a slender column, one may approximate $w$ on the basis of the amplification factor, i.e.,

$$
e+w=e\left(1-\frac{P}{P_{c r}}\right)^{-1}
$$

where $P_{c r}=$ first critical load of column according to elastic theory as in the case of a simply supported (hinged) column; and $P_{c r}=E I \pi^{2} / L^{2}$ where $I=b D^{3} / 12=$ centroidal moment of inertia of cross section.

Substituting (11) into (10), one gets the crack band propagation criterion in terms of $P$, which has the general form

$$
F\left(k, \alpha, h, s, G_{f} ; P\right)=0
$$

(a)

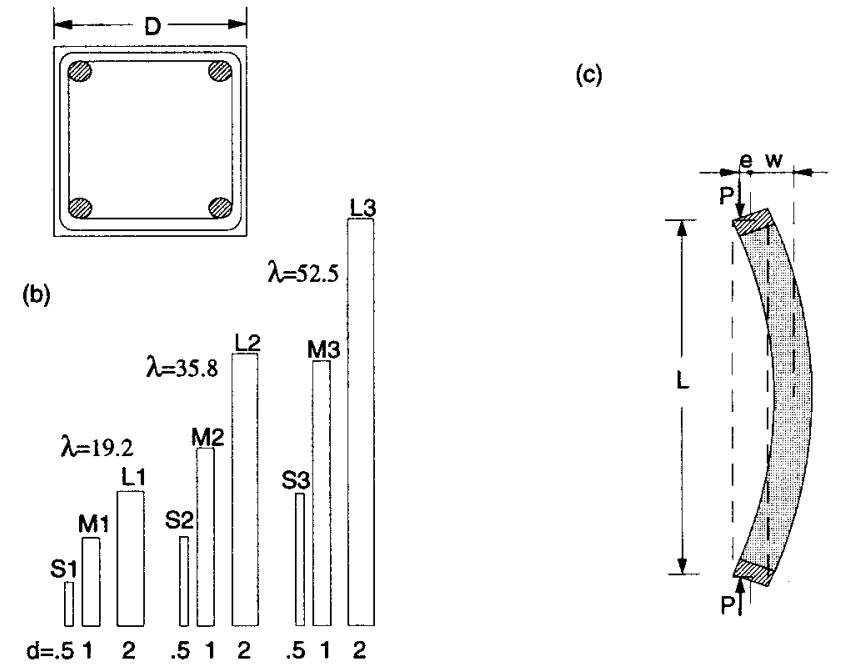

FIG. 4. Reduced Scale Columns with Reduced Size Aggregate Tested by Bažant and Kwon (1994)

To solve for $P$, one needs to know the five previously listed parameters. Of these, only two are free, namely $\alpha$ and $s$, while $G_{f}$ and $h$ are material properties, which must be given, and $k$ can be determined from elasticity, as already mentioned. The constancy of $h$ is the central hypothesis of the present analysis.

The relative crack band length $\alpha$ at maximum load could, in principle, be determined from the criterion of stability loss of the crack band (in the R-curve model, this criterion represents the condition that the energy release curve at constant $P$ be tangent to the R-curve). Experience with other problems shows that application of this criterion usually gives $\alpha$ values that are nearly independent of $D$. For the sake of simplicity, we prefer not to complicate the solution with the condition of crack band stability, and simply assume that the values of the relative crack band length $\alpha=a / D$ for specimens of different sizes are the same. They can be determined by experiments.

Similar to the solution of borehole breakout (Bažant et al. 1993), we may assume that $s$ will be such that the column fails at the first opportunity it has. This means that the value of $s$ can be determined so that $P$ would be minimized. The necessary condition of minimum is

$$
\frac{\partial F}{\partial s}=0
$$

Substituting function $F$ according to (10) and differentiating with respect to $s$, we obtain

$$
-2 k \sigma_{2} \alpha^{2}+2\left(k \sigma_{3}-\bar{h} \sigma_{2}\right) \alpha+\bar{h} \sigma_{3}+\frac{3 h^{3} G_{f}}{2 \pi^{2} s^{3} D}=0
$$

Eqs. (10) and (16) define the solution of the size effect plot of $\sigma_{N}$ versus $D$. After substituting (11), (12), and (2), equation (10) can be rearranged to an equation that is quadratic in $\sigma_{N}$ and of fifth degree in $s$, and (16) can be rearranged to an equation that is linear in $\sigma_{N}$ and of fifth degree in $s$. To obtain a point of the plot, we assume a value of $s$. Then, $\sigma_{N}$ can be - solved from (16) if parameters $G_{f}, a / D$, and $h$ are known. With $\sigma_{N}$ known, $s$ can be reevaluated from (10). This calculation cycle is then iterated, converging to a pair of $\sigma_{N}$ and $P$ values.

Alternatively, one may solve (10) and (16) with the help of the Levenberg-Marquardt nonlinear optimization algorithm. If experimental data on the size effect curve of $\sigma_{N}$ versus $D$ are given, one can use this algorithm to find the values of $G_{f}, a / D$, and $h$ that minimize the sum of squares of the differences between the experimental data and the solution of (10) and (16). 


\section{ASYMPTOTIC SIZE EFFECT FOR LARGE SIZES}

Let us now examine the asymptotic size effect for columns of very large sizes, $D \rightarrow \infty$, under the assumption that $h, \alpha$, and $e / D$ for columns of different sizes are constant. $G_{f}$, as a material property, must of course be constant, too. Analysis of (10) and (16) with (11), (12), and (2) shows that, for $D \rightarrow \infty$, $P \propto b s D^{1 / 2}$ and

$$
s=c_{m} D^{-1 / s}
$$

where $c_{m}=$ certain constant and $\propto=$ proportionality sign. Because $\sigma_{N}=P / b D$, the asymptotic size effect on the nominal strength is

$$
\sigma_{N} \propto s D^{-1 / 2}
$$

or

$$
\sigma_{N} \propto D^{-2 / s}
$$

It is also found that $\sigma_{1} \propto \sigma_{2} \propto \sigma_{3} \propto D^{-2 / 5}$. For the buckling of microslabs, the large-size asymptotic behavior is

$$
\sigma_{c r}=\pi^{2} E s^{2} / 3 h^{2} \propto D^{-2 / s}
$$

For the nominal bending strength $\sigma_{N}^{0}$ of short columns (for which $w \ll e$ ) with similar load eccentricities (same $e / D$ ), we obtain $\sigma_{M}=M D / 2 I=6 P e D / b D^{3} \propto s D^{1 / 2} D D / b D^{3}$ or

$$
\sigma_{M}^{0} \propto s D^{-1 / 2} \propto D^{-2 / 5}
$$

To verify (19), note that the first and second terms in (16) are, for large $D$, of the order of $D^{-2 / 5}$ (note that $\bar{h} \sigma_{2}$ in the second term is of the order of $D^{-9 / 5}$, which is a higher-order small term than $D^{-2 / 5}$ and can, therefore, be neglected in comparison). The last term in (16), proportional to $1 /\left(D^{-3 / 5} D\right)$, is also of the order of $D^{-2 / 5}$. The same type of analysis can be applied to (10).

It is important to note that the asymptotic size effect in compression failure, as indicated in (19), is weaker than in LEFM, for which $\sigma_{N} \propto D^{-1 / 2}$. This difference in the asymptotic size effect, which is the same as previously found for the compression breakout of boreholes in rock (Bažant et al. 1993), is caused by the fact that the spacing $s$ of the axial splitting microcracks is not constant but, according to (17), decreases with size $D$ asymptotically as $D^{-1 / 5}$. This variation of $s$ is the consequence of our minimizing the failure load $P$ with respect to the microcrack spacing. Such minimization is physically correct only if the material inhomogeneities are sufficiently fine. We will comment on that more.

\section{SIZE EFFECT LAW FOR AXIAL COMPRESSION OF STOCKY COLUMN}

The size effect according to (10) and (16) is given implicitly. However, for centric axial compression of a column of negligible slenderness, a simple explicit formula for the size effect can be obtained. For $M=0$, we have $\sigma_{2}=0$ and $\sigma_{1}=$ $\sigma_{3}$. From (10) we get

$$
(2 k \alpha+\bar{h}) \sigma_{3}^{2}-\frac{2 \bar{h} E G_{f}}{s}=0
$$

Then, from (16)

$$
(2 k \alpha+\bar{h}) \sigma_{3}+\frac{3 h^{3} G_{f}}{2 \pi^{2} s^{3} D}=0
$$

From the last two equations, we obtain

$$
\sigma_{3}=-2.21\left[\frac{E^{3} G_{f}^{2}}{(2 k a+h)^{2}}\right]^{1 / 5}
$$

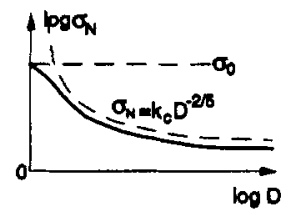

(b)

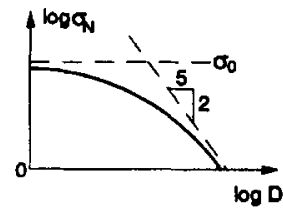

FIG. 5. Size Effect Deduced for Compression Failures: (a) in Linear Scale; (b) in Logarithmic Scale

$$
s=0.41 h\left[\frac{G_{f}}{E(2 k a+h)}\right]^{1 / 5}
$$

and consequently

$$
\sigma_{N}=\sigma_{c r}-\sigma_{3}=\frac{\pi^{2} E s^{2}}{3 h^{2}}+2.21\left[\frac{E^{3} G_{f}^{2}}{(2 k a+h)^{2}}\right]^{1 / s}
$$

Finally, upon rearrangement

$$
\sigma_{N}=2.76\left[\frac{E^{3} G_{f}^{2}}{(2 k a+h)^{2}}\right]^{1 / 5}
$$

Now consider the limit cases of size effect. For $D \rightarrow 0$ (which implies $a \rightarrow 0$ ), we have $\sigma_{N}=2.76\left(E^{3} G_{f}^{2} / h^{2}\right)^{1 / 5}=\sigma_{0}$, representing the material strength limit. For $D \rightarrow \infty$ (which implies $a \rightarrow \infty$ ), we have $\sigma_{N} \rightarrow 0$. Aside from that, we already know that the large-size asymptotic size effect is $\sigma_{N} \propto D^{-2 / 5}$. Based on these results, the size effect plot has the shape shown in Fig. 5.

An explicit formula for $\sigma_{N}$ as a function of $D$ cannot be obtained. It turns out, however, that an explicit formula can be constructed for the inverse relation (as already indicated in Bažant 1994). Indeed, denoting $\bar{\sigma}=\sqrt{2 E G_{f} h / s}$, we can rearrange (22) to the following formula for the inverse size effect law:

$$
\begin{aligned}
a & =\frac{h}{2 k}\left(\frac{\bar{\sigma}^{2}}{\sigma_{3}^{2}}-1\right)=\frac{h}{2 k} \frac{\left(\bar{\sigma}-\sigma_{3}\right)\left(\bar{\sigma}+\sigma_{3}\right)}{\sigma_{3}^{2}} \\
& =\frac{h}{2 k} \frac{\left(\bar{\sigma}-\sigma_{c r}+\sigma_{N}\right)\left(\bar{\sigma}+\sigma_{c r}-\sigma_{N}\right)}{\left(\sigma_{N}-\sigma_{c r}\right)^{2}}
\end{aligned}
$$

in which $\sigma_{N}=P / A$. It may be noted that this formula is quite similar to the following formula obtained by Bažant (1994) after making greater simplifications:

$$
D=D_{0} \frac{\left(\sigma_{0}-\sigma_{P}\right)\left(\sigma_{P}+\sigma_{0}-2 \sigma_{r}\right)}{\left(\sigma_{0}-\sigma_{r}\right)^{2}}
$$

\section{EFFECT OF BUCKLING DUE TO SLENDERNESS}

A more slender column deflects more under the same axial load, and so it stores more strain energy. Consequently, it can also release more energy to drive the crack band, which means one should expect a size effect closer to LEFM, i.e., stronger. Indeed, the reduced scale laboratory experiments of Bažant and Kwon (1994) showed that the size effect in columns becomes more pronounced with increasing slenderness, $D / L$. The question now is how the influence of slenderness on the size effect should be incorporated into (10) and (16). There are two ways to do that.

\section{Simpler Approach Based on Magnification Factor}

The size effect implied in (10) with (16) can be described as $\sigma_{N}=f(D)$ where $f$ is the function implicitly defined by these equations. The consequence of slenderness is to magnify the lateral deflection. The magnification can be approximately calculated as $\mu e$ in which $\mu=\left(1-P / P_{c r}\right)^{-1}=$ magnification factor [e.g., Bažant and Cedolin 1991 (chapter 1)], and $P_{c r}=$ 
first critical load of the column, whose value decreases with increasing slenderness $l / D$. Writing now the same definition of the nominal stress as for small slenderness, and imposing the condition that the stress given by the size effect law be the maximum stress in the deflected slender column, we have

$$
\sigma_{N}=\frac{P}{D}\left(1+\frac{6 e}{D}\right) ; \quad \frac{P}{D}\left[1+\frac{6 e}{D}\left(1-\frac{P}{P_{c r}}\right)^{-1}\right]=f(D)
$$

The size effect plot of $\sigma_{N}$ versus $D$ is the solution of this system of two equations, in which $P$ figures as a parameter to be eliminated. The solutions indicate that, indeed, the size effect is more pronounced for higher slenderness.

\section{Fundamental Approach Based on Additional Energy Release}

From the fracture mechanics viewpoint, the effect of slenderness should be calculated on the basis of the additional energy release engendered by slenderness. This approach is not as simple as the previous one, but is not excessively complicated either. If the column is slender, the release of potential energy from the column must be taken into account. As will now be described, this can be done in the manner outlined in Bažant (1994). We begin by identifying within the column a short segment of length $L$ (Fig. 3) confined between the cross sections at the end of the triangular stress relief zones, having relative displacement $u$ and relative rotation $\theta$.

To make the analysis simple, we may assume that, during the advance of crack band length, $d a$, the values of $u$ and $\theta$ remain constant. This means that the applied load, $P$, the loadpoint displacement $u$ at the column end, and the midheight deflection $w$ all change. In that case, the change of stresses and deformations due to column buckling does not interfere with the triangular energy release zones we considered earlier (Fig. 3). Of course, one could calculate the energy release at fixed load-point displacement or at fixed load. But in that case, the stresses and strains in the unshaded area of the column in Fig. 3 would not remain constant as the band of splitting cracks advances, but would change. This would make it impossible to build on our preceding solution without slenderness effect, and would thus complicate the solution.

The fact that $u$ and $\theta$, rather than the column ends, are considered to be fixed is not objectionable. It is well known in fracture mechanics that the energy release of a fracture specimen can be calculated for different types of load control, e.g., for constant load, or constant deflection, or constant ratio of load and deflection, and always with the same result [e.g., Bažant and Cedolin 1991 (section 12.1)].

Considering the ends of the column to be supported on hinges, we may approximate the deflection curve as $z=w$ $\sin (\pi y / l)$ where $w=$ midheight deflection and $y=$ longitudinal coordinate. The change in the axial force at midheight can be calculated from the change of the stress distribution due to the extension of the band of splitting cracks by $d a$

$$
d P=\left[\sigma_{c r}-\sigma_{0}(a)\right] d a ; \quad d M=\left[\sigma_{c r}-\sigma_{0}(a)\right]\left(\frac{P}{2}-a\right) d a
$$

where $\sigma_{c r}=$ critical stress of microslabs. The axial load, $P$, is assumed to have constant eccentricity $e$ at both ends of the column, and so $M=P(e+w)$ or $w=(M / P)-e$. Differentiating, we have

$$
d w=[d M-(e+w) d P] / P
$$

The axial shortening due to deflection $w$ is $u=\int_{0}^{l}\left(z^{\prime}\right)^{2} / 2 d y=$ $\pi^{2} w^{2} / 4 l$, and so the work of $P$ during $d a$ is

$$
d W=P d u=\frac{\pi^{2} P w}{2 l} d w
$$

The change of stored bending energy during $d a$ is $d U=$ $d \int_{0}^{l} E I\left(z^{\prime \prime}\right)^{2} / 2 d y=d\left(\pi^{4} E l w^{2} / 4 l^{3}\right)$, that is,

$$
d U=\pi^{2} E l w d w / 2 l^{3}
$$

where $I=b D^{3} / 12$ = centroidal moment of inertia of cross section of column.

The change of potential energy due to axial strains is $d \Pi_{a}$ $=-d\left(P^{2} l / 2 E A\right)$ where $A=b D=$ cross section area of the column. Now the change of potential energy due to column deformation during crack band advance $d a$ is given by

$$
d\left(\Delta \Pi_{a}\right)=\mathscr{G}_{2} d a=-\frac{\pi^{2}}{2 l}\left(P_{c r}-P\right) w d w-\frac{l}{E A} P d P
$$

where $P_{c r}=\pi^{2} E I / l^{2}=$ first critical load of hinged column. Integrating (35), we obtain the following expression for the additional energy release that needs to be added to that calculated before in (8):

$$
\Delta \Pi_{a}=\left[\frac{\pi^{2}}{2} e\left(e+w-a+\frac{D}{2}\right)+\frac{P l^{2}}{E A}\right]\left(\alpha \sigma_{2}-\sigma_{3}\right)
$$

It may now be noted that if the column is axially very stiff and $P=P_{c r}$, there is no energy release due to column deformation, as expected. When $P<P_{c r}$, there is a positive energy release because $P d w$ and $P d P$ are negative during crack band extension. The additional energy release must obviously promote fracture, and thus it must intensify the size effect.

The subsequent calculation is the same as that which led to (10) and (16). One finds that the following terms need to be added to the left-hand sides of (10) and (16), respectively:

$$
\begin{gathered}
A_{1}=-6 A_{2}\left(\alpha \sigma_{2}-\sigma_{3}\right) \\
A_{2}=-\left[\frac{E \pi^{2}}{2 l^{2}} e\left(e+w+\frac{D}{2}-a\right)+\frac{P}{A}\right]
\end{gathered}
$$

The size effect curves for a slender column calculated on the basis of the additional energy release and on the basis of the magnification factor will further be discussed when they are compared with the test data in the next section. The size effect curve obtained when the slenderness is neglected is also shown.

\section{COMPARISON WITH EXPERIMENTAL DATA}

At present, apparently the only test data by which the present theory can be checked are the data reported by Bažant and Kwon (1994). Other tests of concrete columns either did not involve different sizes, or did not feature a sufficient size range. Some did not adhere to geometrical similarity (in which case inaccurately modeled shape effects are superimposed on the size effect, making the evaluation more uncertain).

Bažant and Kwon tested, at Northwestern University, reduced-scale reinforced concrete columns of square cross section (Fig. 4). Three different sizes $D$ for each of three different slendernesses $l / D$ were tested. The size ratio was $1: 2: 4$; the cross section sides were $D=12.7,25.4$, and $50.8 \mathrm{~mm}(0.5,1$, and 2 in.); and the slendernesses were $l / D=19.2,35.8$, and 52.5. The reinforcement, which was scaled in proportion to $D$, consisted of four longitudinal bars in the corners of the square cross section [diameters $1.59,3.18$, and $6.35 \mathrm{~mm}(1 / 16,1 / 8$, and $1 / 4 \mathrm{in}$. )] and of ties [diameters $0.79,1.59$, and $3.18 \mathrm{~mm}$ $(1 / 32,1 / 16$, and $1 / 8$ in.)] spaced at $7.62,15.2$, and $30.5 \mathrm{~mm}$ $(0.3,0.6$, and 1.2 in.). Portland cement microconcrete of maximum aggregate size $3.35 \mathrm{~mm}$ (0.132 in.) was used. The concrete cover of the bars was also scaled. For further details see Bažant and Kwon (1994).

The test data are analyzed under the assumption that, for columns of different sizes as well as different slendernesses, the crack band width $h$, rather than the relative width $h / D$, is 


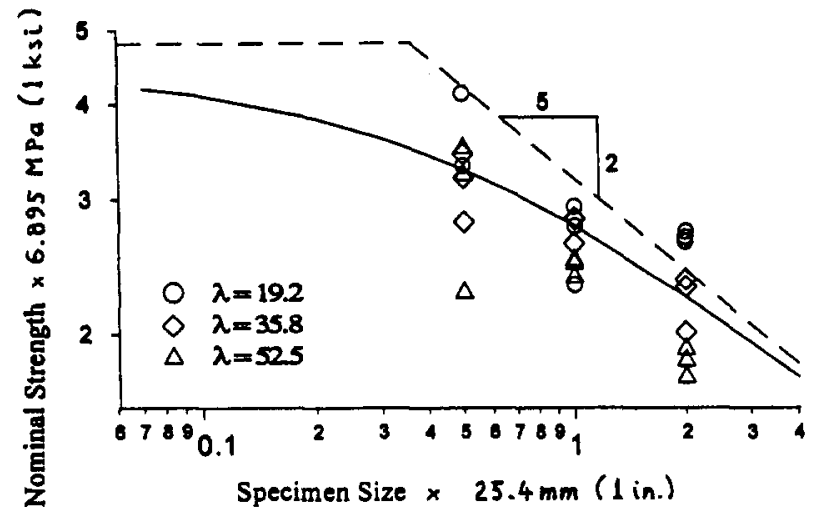

FIG. 6. Measured Size Effect Compared to Theoretical Size Effect when Slenderness 18 Neglected [Solid Lines, Coefficlent of Variation of Devlations $\omega=14 \%, a / D=.22, h=33 \mathrm{~mm}(1.3 \mathrm{in}$.), $G,=15.6 \mathrm{~N} / \mathrm{m}(0.089 \mathrm{lb} / \mathrm{in})$.
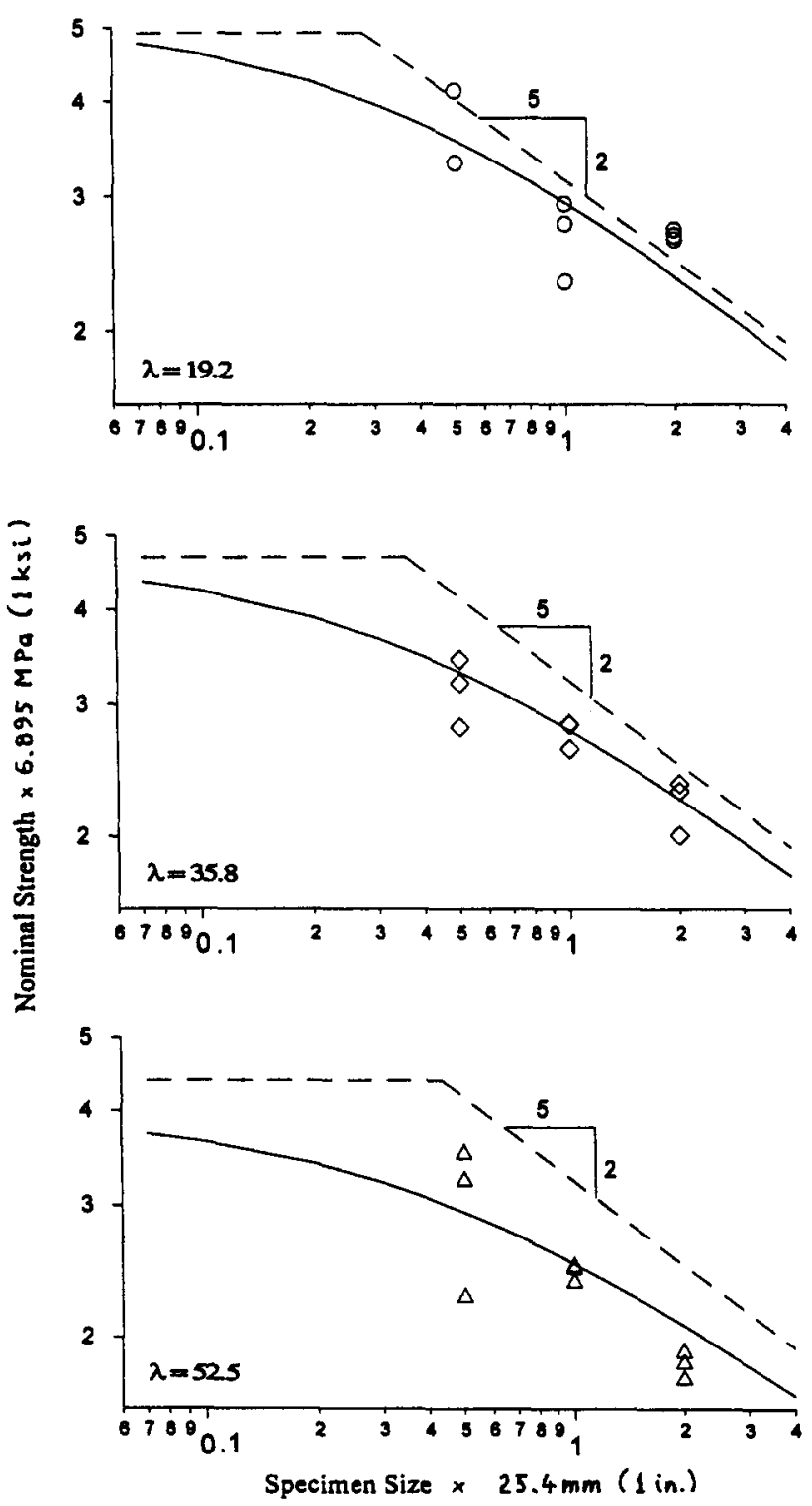

FIG. 7. Measured Size Effect Compared to Theoreticel Size Etfect with Slenderness Effect Based on Magnification Factor [Solld Lines, Coefficlent of Variation of Deviations $\omega=12.7 \%$, $\left.a / D=.27, h=27.9 \mathrm{~mm}(1.1 \mathrm{ln}),. G_{f}=22.2 \mathrm{~N} / \mathrm{m}(0.127 \mathrm{lb} / \mathrm{in}).\right]$ constant. A reasonable assumption is that the crack band width is roughly proportional to the material length, $l$ (the same assumption is reasonable for tensile crack bands). The material length is related to the maximum inhomogeneity size, i.e., the maximum aggregate size in the case of concrete, or to the combination of fracture energy and tensile strength $f_{t}^{\prime}$ of the material having a dimension of length, namely Irwin's characteristic length $l_{c h}=E G_{f} / f_{i}^{\prime 2}$. It has been checked that the assumption of constant $h$ agreed with the test results much better than the assumption of constant $h / D$.

The values of $a / D$ have also been assumed constant for columns of different sizes, including those of different slendernesses. In this regard, it may be noted that differences in slenderness cannot represent important deviations from geometrical similarity of failure mode because, according to SaintVenant's principle, the addition of mass to the column ends, making the column longer, cannot appreciably affect the stress field in the fracturing zone in the middle of the columns.

Comparison of the present theory with these data is shown in Figs. 6-8. The solid lines show the theoretical results, and the data points show the test results. Fig. 6 gives the results

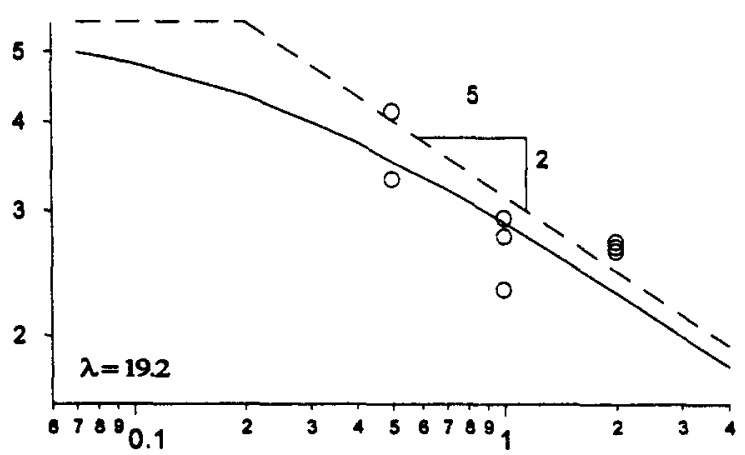

(a)
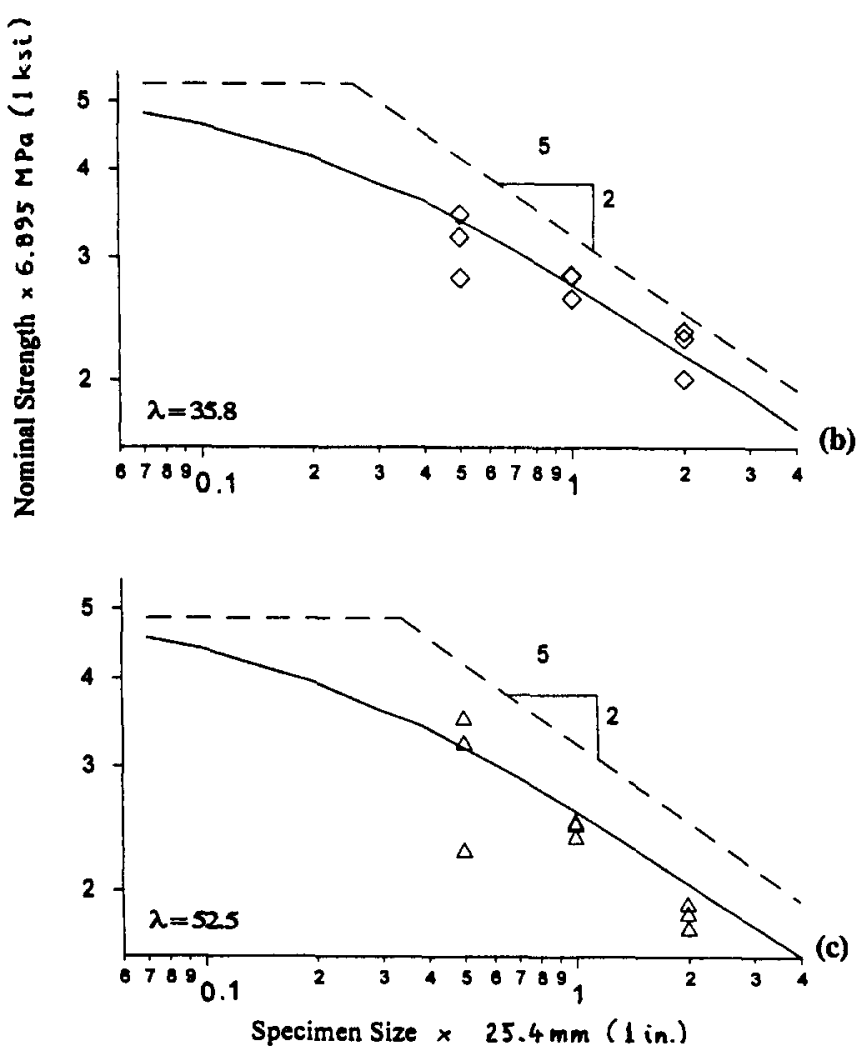

FIG. 8. Measured Size Effect Compared to Theoretical Size Effect with Slenderness Effect Based on Additional Energy Release [Solld Lines, Coefficient of Variation of Deviations $\omega=$ $12.2 \%$, $a / D=.25, h=23.1 \mathrm{~mm}$ (0.91 in.), $G,=16.62 \mathrm{~N} / \mathrm{m}(0.095$ $\mid \mathrm{b} / \ln )$.

JOURNAL OF ENGINEERING MECHANICS / FEBRUARY 1997 / 169 
TABLE 1. Parameters for Optimization of Test Data

\begin{tabular}{c|c|c|c}
\hline \hline $\begin{array}{c}\text { Approaches } \\
(1)\end{array}$ & $\begin{array}{c}\text { Slenderness } \\
\text { neglected } \\
(2)\end{array}$ & $\begin{array}{c}\text { Magnification } \\
\text { factor } \\
(3)\end{array}$ & $\begin{array}{c}\text { Additional energy } \\
\text { release } \\
(4)\end{array}$ \\
\hline$a / D$ & 0.221 & 0.276 & 0.255 \\
$h$ & $33.6 \mathrm{~mm}(1.322 \mathrm{in})$. & $28.6 \mathrm{~mm}(1.125 \mathrm{in})$. & $23.1 \mathrm{~mm}(0.91 \mathrm{in})$. \\
$G_{f}$ & $15.5 \mathrm{~J} / \mathrm{m}(0.089 \mathrm{lb} / \mathrm{in})$. & $19.7 \mathrm{~J} / \mathrm{m}(0.112 \mathrm{lb} / \mathrm{in})$. & $16.7 \mathrm{~J} / \mathrm{m}(0.095 \mathrm{lb} / \mathrm{in})$. \\
$\omega$ & 0.137 & 0.127 & 0.122 \\
\hline
\end{tabular}

when the slenderness effect is neglected. Fig. 7 shows the comparisons for the simpler analysis of slenderness effect based on the magnification factor. Fig. 8 shows the analysis of slenderness effect based on the additional energy release. The optimized parameters of the three different methods of analysis giving the best fit of the test data are listed in Table 1 .

As seen from Figs. 7 and 8, the present method, with both the simplified and the additional energy release approaches to the slenderness effect, can represent the test results for the reduced-scale columns quite well. It may also be noted that the size effect, which is neglected by the present code specifications, is quite significant. Size effect tests of columns of normal sizes and with normal size aggregate are, of course, needed.

\section{SPECIAL CASE: COMPRESSION WITH TRANSVERSE EXTENSION (SHEAR FAILURE)}

Finally, we should at least mention an important and particularly simple special modification (Bažant 1996) of the previous mechanism that occurs under shear loading or, equivalently, under compression loading accompanied by large transverse tensile strain. In that case, a system of major continuous parallel cracks in the direction of compression may develop before the maximum compression load [Fig. 9(c)]. These cracks are not axial splitting cracks but are produced by transverse tension. If a sufficient restraint is provided, the opening of these cracks does not localize into a single crack. An example is the formulation of diagonal cracks under shear loading of a concrete beam in which a restraint is provided by the longitudinal reinforcement and stirrups [Fig. 9(d)]. The transverse tensile stress and the diagonal cracks caused by it have a large effect on the compression behavior in the direction of the cracks (Hsu 1988, 1993).

When a transverse tensile crack forms in an isotropic specimen, the stress is relieved approximately from the shaded triangular areas shown in Fig. 9(a) whose height is about the same as the width. But when a transverse tensile crack forms in a highly orthotropic specimen under tension, for example a

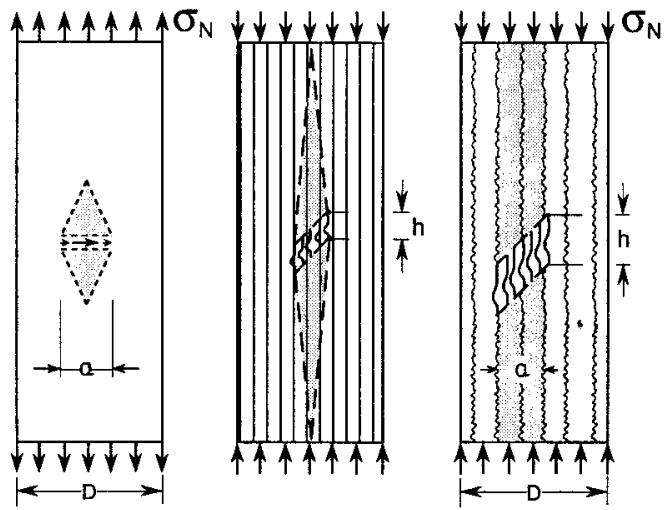

(a) (b) (c) unidirectional fiber composite, the triangular stress relief zones from which strain energy is released are extremely elongated, with sides almost parallel to the direction of fibers [Fig. 9(b)]. The same is true for compression loading when a transverse slit is cut out. From this analogy, it is clear that a system of continuous parallel tensile cracks can also cause a material such as concrete to become highly orthotropic on the macroscale. The stress relief zone of a transversely propagating band of axial splitting microcracks can then become nearly a strip, which is limited by parallel tensile cracks and is shown as the shaded strip in Fig. 9(c) (Bažant 1996).

The energy released from the shaded strip in Fig. 9(c), from which the stress is relieved by the band, is easily expressed as

$$
\Delta \Pi=\frac{\sigma_{N}^{2}}{2 E} b a D
$$

in which $\sigma_{N}=$ applied, initially uniform, axial compressive stress. The energy consumed (dissipated) by the band of axial splitting microcracks is $W_{f}=G_{f} b h a / s$. The energy balance during the propagation of the band requires that $-\partial \Delta \Pi / \partial a=$ $\partial W_{f} / \partial a$. This yields the relation $\left(\sigma_{N}^{2} / 2 E\right) D=G_{f} h / s$, from which (Bažant 1996)

$$
\sigma_{N}=C_{P} D^{-1 / 2} ; \quad C_{P}=\sqrt{2 E G_{f} h / s}
$$

where $C_{P}=$ constant. So we see that this special mechanism of energy release, which is characteristic of the shear failure of concrete, also yields a size effect.

The size effect obtained, being of LEFM type, is very strong; however, this is due to the fact that the width $h$ of the band of splitting microcracks has been considered constant. In reality, $h$ may be expected to become constant only after a certain initial growth, as approximately described by the equation $h=h_{0} a /\left(c_{0}+a\right)$ where $h_{0}$ and $c_{0}$ are material constants. In that case, the size effect obtained for the shear failure of reinforced concrete beams with or without stirrups is obtained in the same form as Bažant's (1984) original size effect law. See Bažant (1996), in which the truss model (e.g., Hsu 1993) (or strut-and-tie model) is modified to calculate the energy release due to localized crushing of compression struts and simple formulas are derived for the size effect in beams with or without stirrups.

\section{QUESTION OF VARIATION OF MICROCRACK SPACING WITH SIZE D}

By minimizing load capacity $P$, we found in (17) that the spacing of the splitting microcracks $s=c_{m} D^{-1 / 5}$ where $c_{m}=$ (d)

FIG. 9. Energy Release Zones of: (a) Tensile Crack in Highly Orthotropic Elastic Material; (b) Band of Compression Splitting Cracks in Concrete with System of Parallel Macrocracks due to Transverse Tension Loading; (c) Application to Size Effect in Failure of Compression Struts in Reinforced Concrete Beam with Stirrups under Shear Loading [after Bažant (1996)] 
constant. Strictly speaking, however, a continuous variation of crack spacing with the structure size is possible only for homogeneous materials. For highly heterogeneous materials such as concrete, the dominant spacing of the main splitting microcracks must be an integer multiple of the dominant spacing of the largest aggregate pieces, $s_{0}$. Therefore, spacing $s$ can vary only by jumps from one integer multiple of $s_{0}$ to the next. Its value may be taken as the positive integer multiple as close to $c_{m} D^{-1 / 5}$ as possible, i.e.

$$
s=s_{0} \operatorname{Int}\left[0.5+\left(c_{m} D^{-1 / 5} / s_{0}\right)\right] \text { but } s \geq s_{0}
$$

This means that for finite large intervals of the size range, the dominant microcrack spacing $s$ cannot change in the case of a highly heterogeneous material such as concrete. It is easy to adjust the preceding analysis for the case of constant spacing $s$. A constant rather than variable $s$ needs to be substituted into (18), (20), and (21). The main difference is that, instead of (19), the asymptotic size effect then becomes

$$
s \propto D^{-1 / 2}
$$

which is the same as for all the types of tensile failure studied before (e.g., Bažant 1984).

The materials that are not sufficiently heterogeneous for being characterized by (41) and (42) probably include finegrained rocks such as limestone, ceramics, and pure ice, and probably exclude concrete.

\section{CONCLUSIONS}

1. Quasibrittle compression failure of concrete columns may be considered to be triggered by the formation of axial splitting cracks. It can be approximately modeled as the propagation of a band of axial splitting cracks (microcracks) in a direction orthogonal or inclined to the direction of propagation. When the direction is inclined, the final failure surface may appear as a shear failure even though shear slip might not be the mechanism controlling the maximum load.

2. The maximum load of centrically or eccentrically loaded columns can be calculated from the energy balance condition, stating that the energy released from the column as a result of crack band advance must be equal to the energy consumed by formation of new axial splitting cracks at the tip of the crack band.

3. The residual compressive stress transmitted across the band is governed by buckling of the microslabs of the material between the axial splitting cracks. Compatibility of strains must be considered to determine the final postbuckling deflections of the microslabs. The work during the postbuckling deflections of the microslabs must be taken into account in the energy balance.

4. The spacing $s$ of the axial microcracks (or the thickness of the microslabs) can be determined from the condition that the failure load must be minimum. It is found that the spacing decreases with the cross section size $D$ as $D^{-1 / 5}$, provided that the material inhomogeneities (such as the aggregate size in concrete) are not so large as to prevent a continuous decrease of $s$.

5. The proposed model exhibits size effect. In the limit of small sizes $D$, the size effect disappears, which corresponds to plastic limit analysis. In the limit of large sizes $D$, the size effect on the nominal strength of the column $\sigma_{N}$ approaches the power law $D^{-2 / 5}$ (which is the same as that previously found for the compression breakout of boreholes). The reason that this differs from the power law $D^{-1 / 2}$ characteristic of LEFM is the aforementioned variation of spacing $s$ of the axial splitting microcracks. However, if the decrease of $s$ with increasing $D$ is pre- cluded by large enough material inhomogeneities, then $\sigma_{N}$ approaches the power law $D^{-1 / 2}$, the same as in LEFM.

6. The theory predicts the size effect to intensify when the slenderness of the column increases. The intensified size effect can be explained by an increase of the strain energy stored in the column with structure size $D$.

7. The results of previous tests on reduced-scale tied reinforced concrete columns of different sizes and different slendernesses are described by the present model quite well.

8. When a quasi-brittle material fails due to a compression loading combined with transverse tension, as is typical of the shear failure of reinforced-concrete beams, a system of parallel tensile cracks may be produced before the maximum load is reached in compression. Then one may use a special, particularly simple modification of the proposed theory in which the stress-relief zone releasing energy consists approximately of a strip in the direction of tensile cracks (this is treated in detail in Bažant 1996).

\section{ACKNOWLEDGMENT}

The research was supported partly under National Science Foundation grant MSS-911447-6, to Northwestern University, and partly under a grant from the Center for Advanced Cement-Based Materials at Northwestern University.

\section{APPENDIX. REFERENCES}

Ashby, M. F., and Hallam, S. D. (1986). "The failure of brittle solids containing small cracks under compressive stress states." Acta Metall. Mat., 34(3), 497-510.

Batto, R. A., and Schulson, E. M. (1993). "On the ductile-to-brittle transition in ice under compression." Acta Metall. Mat., 41(7), 22192225.

Bažant, Z. P. (1967). "Stability of continuum and compression strength." Bull. RILEM, 39, 99-112, Paris (in French).

Bažant, Z. P. (1968). "Effect of folding of reinforcing fibers on the elastic moduli and strength of composite materials." Mekhanika Polimerov, 4, 314-321, Riga (in Russian).

Bažant, Z. P. (1994). "Size effect in tensile and compressive quasibrittle failures." Size effect in concrete structures, Proc., Japan Concrete Inst. lnt. Workshop, Tohoku Univ., Sendai, Japan, H. Mihashi, H. Okamura, and Z. P. Bażant, eds., FN Spon, London, 161-180.

Bažant, Z. P. (1996). "'Fracturing truss model; explanation of size effect mechanism in shear failure of reinforced concrete." Rep. 96-3/603f, Dept. of Civ. Engrg., Northwestern Univ., Evanston, IIl. [J. Engrg. Mech., ASCE, 123(2)].

Bažant, Z. P., and Cedolin, L. (1991). Stability of structures: elastic, inelastic, fracture and damage theories. Oxford University Press, New York, N.Y.

BaŽant, Z. P., and Kwon, Y. W. (1994). "Failure of slender and stocky reinforced concrete columns: tests of size effect." Mat. and Struct., 27, 79-90, Paris.

Bažant, Z. P., Lin, F.-B., and Lippmann, H. (1993). "Fracture energy release and size effect in borehole breakout." Int. J. Num. and Anal. Methods in Geomech, 17, 1-14.

BaŽant, Z. P., and Ožbolt, J. (1992). "Compression failure of quasibrittle material; nonlocal microplane model.' J. Engrg. Mech., ASCE, 118(3), 540-556.

Bažant, Z. P., and Xiang, Y. (1994). "Compression failure of quasibrittle materials and size effect." AMD Symp. Ser. ASME Appl. Mech. Div., 185, Damage mechanics in composites, ASME Winter Annual Meeting. Chicago, D. H. Allen and J. W. Ju, eds., 143-148.

Bieniawski, Z. T. (1974). "Estimating the strength of rock materials." $J$. S. Afr. Inst. Min. Metal, 74, 312-320.

Biot, M. A. (1965). Mechanics of incremental deformations. John Wiley \& Sons, Inc., New York, N.Y.

Blanks, R. F., and McNamara, C. C. (1935). "Mass concrete tests in large cylinders." J. Am. Concrete Inst., 31, 280-303.

Carter, B. C. (1992). "Size and stress gradient effects on fracture around cavities." Rock Mech. and Rock Engrg., 25(3), 167-186.

Carter, B. C., Lajtai, E. Z., and Yuan, Y. (1992). "Tensile fracture from circular cavities loaded in compression." Int. J. Fracture, 57, 221236. 
Cotterell, B. (1972). "Brittle fracture in compression." Int. J. Fracture Mech., 8(2), 195-208.

Cotterell, B., and Rice, J. R. (1980). "Slightly curved or kinked cracks." Int. J. Fracture, 16, 155-169.

Droz, P., and Bažant, Z. P. (1989). "Nonlocal analysis of stable states and stable paths of propagation of damage shear bands." Cracking and damage, Proc., France-U.S. Workshop, Cachan, France, J. Mazars and Z. P. Bažant, eds., Elsevier, London, 183-207.

Fairhurst, C., and Cornet, F. (1981). "Rock fracture and fragmentation." Rock mechanics: from research to application. Proc., 22nd U.S. Symp. on Rock Mech., H. H. Einstein, ed., MIT Press, Cambridge, Mass., $21-46$.

Gonnermann, H. F. (1925). "Effect of size and shape of test specimen on compressive strength of concrete." Proc., ASTM, ASTM, Philadelphia, Pa., 25, 237-250.

Haimson, B. C., and Herrick, C. G. (1985). "In-site stress calculation from borehole breakout experimental studies." Research and engineering applications in rock masses. Proc., 26th U.S. Symp. on Rock Mech., E. Ashworth, ed., A. A. Balkema, Rotterdam, The Netherlands, $1207-1218$

Hoek, E., and Bieniawski, Z. J. (1965). "Brittle fracture propagation in rock under compression." Int. J. Fracture Mech., 1, 137-155.

Horii, H., and Nemat-Nasser, S. (1982). "Compression-induced nonplanar crack extension with application to splitting, exfoliation and rockburst." J. Geophys. Res., 87, 6806-6821.

Horii, H., and Nemat-Nasser, S. (1986). "Brittle failure in compression, splitting, faulting and brittle-ductile transition." Phil. Trans. Royal Soc., Royal Society, London, 319(1549), 337-374.

Hsu, T. T. C. (1985). "Softened truss model theory for shear and torsion." ACI Struct. J., 85(6), 624-635.

Hsu, T. T. C. (1993). Unified theory of reinforced concrete. CRC Press, Inc., Boca Raton, Fla.

Ingraffea, A. R. (1977). "Discrete fracture propagation in rock: laboratory tests and finite element analysis," PhD dissertation, Univ. of Colorado, Boulder.

Ingraffea, A. R., and Heuzé, F. E. (1980). "Finite element models for rock fracture mechanics." Int. J. Numer. and Anal. Meth. in Geomech., 4. 25 .

Jishan, X., and Xixi, H. (1990). "Size effect on the strength of a concrete member." Engrg. Fracture Mech., 35, 687-696.

Kachanov, M. (1982). "A microcrack model of rock inelasticity-part I. Frictional sliding on microcracks." Mech. of Mat., 1, 19-41.

Kemeny, J. M., and Cook, N. G. W. (1987). "Crack models for the failure of rock under compression." Proc., 2nd Int. Conf. on Constitutive Laws for Engrg. Mat., C. S. Desai et al., eds., Elsevier Science Publishing Co., Inc., New York, N.Y., 2, 879-887.
Kemeny, J. M., and Cook, N. G. W. (1991). "Micromechanics of deformation in rock." Toughening mechanisms in quasibrittle materials, $\mathbf{S}$. P. Shah et al., eds., Kluwer, Dordrecht, The Netherlands, 155-188.

Kendall, K. (1978). "Complexities of compression failure." Proc., Royal Soc., Royal Society, London, A(361), 245-263.

Marti, P. (1989). "Size effect on double punch tests on concrete cylinders." ACI Mat. J., 86(6), 597-601.

Murakami, Y. (1987). Stress intensity factors handbook. Pergamon Press, Inc., Tarrytown, N.Y.

Nemat-Nasser, S., and Obata, M. (1988). "A microcrack model of dilatancy in brittle material." ASME J. Appl. Mech., 55, 24-35.

Nesetova, V., and Lajtai, E. Z. (1973). "Fracture from compressive stress concentration around elastic flaws." Int. J. Rock Mech. and Min. Sci., 10, 265-284.

Palmer, A. C., and Sanderson, T. J. O. (1991). "Fractal crushing of ice and brittle solids." Proc., Royal Soc., Royal Society, London, A(443), $469-477$.

Paul, B. (1968). "Macroscopic criteria for plastic flow and brittle fracture." Fracture, an advanced treatise, H. Liebowitz, ed., 2, chapter 4.

Sammis, C. G., and Ashby, M. F. (1986). "The failure of brittle porous solids under compressive stress state." Acta Metall. Mat., 34(3), 511-526.

Schulson, E. M., and Nickolayev, O. Y. (1995). "Failure of columnar saline ice under biaxial compression: failure envelopes and the brittleto-ductile transition." J. Geophys. Res., 100(B11), 22383-22400.

Shetty, D. K., Rosenfield, A. R., and Duckworth, W. H. (1986). "Mixed mode fracture of ceramics in diametrical compression." J. Am. Ceram. Soc., 69(6), 437-443.

Steif, P. S. (1984). “Crack extension under compressive loading.' 'Engrg. Frac. Mech., 20, 463-473.

Tada, H., Paris, P. C., and Irwin, G. R. (1985). The stress analysis of cracks handbook, 2nd Ed., Paris Productions, Inc., St. Louis, Mo.

van Mier, J. G. M. (1986). "Multiaxial strain-softening of concrete." Mat. and Struct., 19, 179-200, Paris.

Wittmann, F. H., and Zaitsev, Y. V. (1981). "Crack propagation and fracture of composite materials such as concrete." Proc., 5th Int. Conf. on Fracture (ICF5).

Yuan, Y. Y., Lajtai, E. Z., and Ayari, M. L. (1993). "Fracture nucleation from a compression-parallel finite-width elliptical flaw." Int. J. Rock Mech. and Min. Sci., 30(7), 873-876.

Zaitsev, Y. V. (1985). "Inelastic properties of solids with random cracks." Mechanics of geomaterials, Z. P. Bažant, ed., John Wiley \& Sons, Inc., New York, N.Y., 89-128.

Zaitsev, Y. V., and Wittmann, F. H. (1981). "Simulation of crack propagation and failure of concrete." Mat. and Struct., 14, 357-365, Paris. 